\title{
Desenvolvimento de um ambiente de exibição gráfica para um espectrômetro USB.
}

\author{
$\underline{\text { Rafael Costa dos Santos }}{ }^{1}$; Germano Pinto Guedes ${ }^{2}$; \\ 1. Bolsista Probic-UEFS, Graduando em Física, Universidade Estadual de Feira de Santana, e-mail: \\ Rafaelc490@gmail.com \\ 2. Orientador, Departamento de Física, Universidade Estadual de Feira de Santana, e-mail: Germano@uefs.br
}

PALAVRAS-CHAVE: Espectrômetro; Instrumentação; Sensoriamento.

\section{INTRODUÇÃO}

Quanto mais o tempo passa se tornam cada vez mais necessários conhecimentos tecnológicos na ciência, pois hoje, todos os fenômenos não solucionados precisam de uma visão mais precisa para serem explicados e o alcance desta explicação depende de todo um conhecimento de programação e sensoriamento que devem andar de mãos dadas com os cientistas em prol de novas descobertas. A capacidade de desenvolver sua própria instrumentação é um fator determinante para a maturidade científica de um país. $\mathrm{O}$ Espectrômetro[3] é um instrumento voltado ao sensoriamento do comportamento de espectros eletromagnéticos[6], o mesmo tem a capacidade de realizar aquisições sobre intensidade e comprimento de onda de um espectro. O espectro eletromagnético pode conter informações muito importantes, estas que vão desde detecção de gases em um meio até por exemplo, trazer informações sobre a temperatura de um corpo baseada no comprimento de onda que possui um pico de intensidade da radiação que um corpo emite. Ao estudo e aplicação de todas as importantes funções do espectro eletromagnético deu-se o nome de espectroscopia, conjunto de métodos para análise de substâncias, baseados na produção e interpretação de seus espectros de emissão ou absorção de radiações eletromagnéticas.

O projeto teve seu foco no aprendizado em desenvolver um ambiente de exibição gráfica, este que seria desenvolvido em uma linguagem de programação escolhida para criar um ambiente onde se pudesse realizar a exibição de dados em tempo real. O projeto foi pensado para que o futuro cientista obteve-se uma gama considerável de novos conhecimentos em espectroscopia e automação, o que sem dúvida contribui para a formação de um cientista que acompanhará os avanços da utilização de ferramentas tecnológicas no mundo científico. Um dos fatores mais importantes do projeto é que o apredizado em criar ambientes de exibição para aquisições em um hardware como o espectrômetro, fornesce conhecimentos de como operar equipamentos científicos atravéz de programação fazendo-os operar da maneira que a pesquisa necessita possibilitando a solução de contornar limitações em software de fabricantes. 


\section{MATERIAL E MÉTODOS}

\section{- Materiais}

- Espectrômetro Red Tide Ocean Óptics

- Fibra óptica

- Computador Windows 7

- IDE MATLAB R2015a

\section{- Métodos}

\section{-Comunicação com espectrômetro}

Desenvolver escritas em linguagem de programação, realizar testes de conexão utilizando APIS desenvolvidas pelo fabricante das quais possibilitam a comunicação com o hardware.

-Desenvolvimento de um Ambiente para exibição gráfica

Após o estabelecimento de comunicação entre o ambiente de escrita da linguagem de programação e o hardware do espectrômetro, realizar pesquisas em datasheets e outras literaturas na rede noções que levem a caminhos para construção da rotina de programação envolvendo aquisição, armazenamento organizado em tabela e exibição gráfica dos dados.

-Estudo da espectroscopia para conpreensão do hardware

Pesquisar em literaturas informações sobre a espectroscopia, trazendo assim noções sobre o funcionamento do espectrômetro. Fixar o conhecimento utilizando o espectrômetro para realizar experimentos de espectroscopia.

- Estudo da linguagem de programação

Estudar sobre o espectrômetro, seu hardware e entender como o mesmo foi pensado. Estudar como o programar e entender sobre os dados de calibração armazenados em sua memória EEPROM caso necessário. Pesquisar e testar linguagens de programação e encontrar uma que mais apresente vantagens na sua utilização para a realização da automação do espectrômetro. 


\section{RESULTADOS E/OU DISCUSSÃO}

- Desenvolvimento da interface para exibição gráfica

Utilizando a implementação da API de nome WRAPPER a rotina de aquisição de dados apresentou funcionalidade, desta forma o desenvolvimento da interface gráfica obteve êxito. Após a rotina de programação apresentar êxito para aquisição de dados, o foco do projeto se voltou em construir um ambiente amigável, para isto, a IDE da linguagem MATLAB oferece uma plataforma denominada GUIDE. A plataforma GUIDE oferece uma gama de possibilidades para uma interação mais amigável possível com o usuário do ambiente, é possível criar botões, ambiente gráfico das aquisições e tabelas para uma aquisição mais organizada e limpa dentre outras funções.

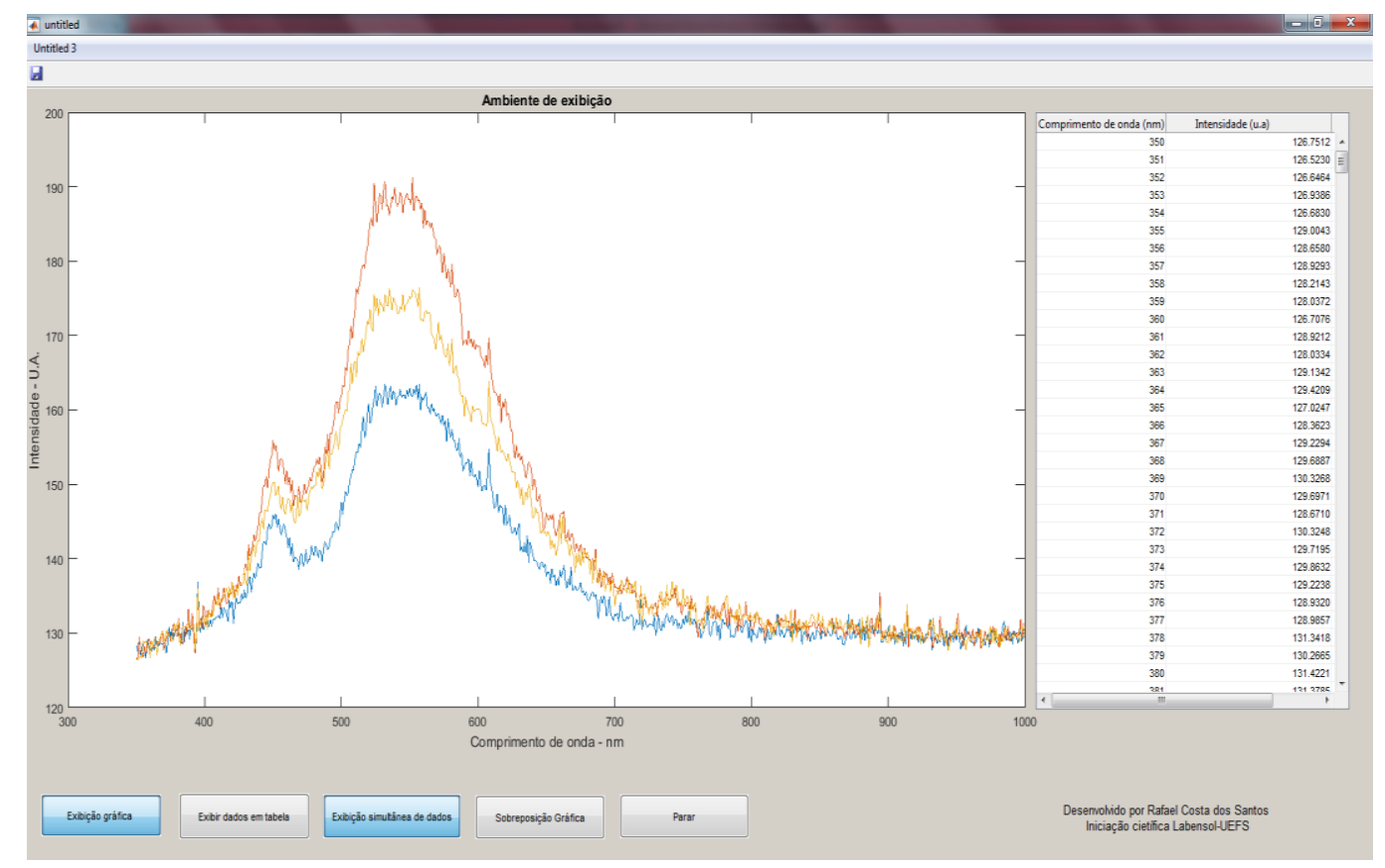

Figura1. Ambiente em funcionamento

Acima vemos o ambiente em funcionamento (figura 1). $\mathrm{O}$ ambiente está realizando aquisição de dados provenientes de um espectro vindo da lâmpada incandescente utilizada para teste do seu funcionamento. O programa possui botões para exibição gráfica, armazenamento em tabela e função para plotagem de vários espectros num mesmo ambiente gráfico. 


\section{CONSIDERAÇÕES FINAIS}

O objetivo do projeto proposto foi realizar automação do espectrômetro USB para o desenvolvimento de um ambiente de exibição gráfica, pensado nisto foram estudadas e praticadas técnicas para a realização do feito que apresentou funcionalidade. $\mathrm{O}$ ambiente funciona, realiza aquisição de dados e os plota graficamente além de escrever os mesmos em tabela de maneira organizada. A IDE da MATLAB possui funcionalidades incríveis, surgindo a necessidade futura para uma implementação de banco de dados, por exemplo, com certeza a mesma conseguirá suprir, pois a MATLAB, é uma linguagem de grande poder e mostra não dever nada as demais linguagens. Uma vez que o ambiente funciona, agora é possível utilizar do conhecimento de automação do hardware para aplicação em projetos futuros.

\section{REFERÊNCIAS}

1) LINE ARRAY SENSOR COMPARISON. DANIEL T, MCCORMICK. Acesso em < http:// www.advancedmems.com/pdf/amems_linesensorarraysummary_v1.pdf $>$. Data de acesso: 10/08/2017.

2) BASICS OF SPECTRAL MEASUREMENT. JETI TECHNISCHE INSTRUMENT. Acesso em <http://www.jeti.com/cms/images/jeti_com/down/basics/basics.pdf > . Data de acesso: 20/09/2017.

3) ESPECTROMETER USB RED TIDE. OCEAN ÓPTICS. Acesso em < https://ocean optics.com/product/usb-650-red-tide-spectrometers/>. Data de acesso: 16/10/2017

4) OMINIDRIVER PROGRAMING MANUAL. OCEAN ÓPTICS. Acesso em <https://ocean optics.com/wpcontent/uploads/omnidriver_programming_manual.pdf $>$. Data de acesso: 22/11/2017.

5) NOÇÕES BÁSICAS DE PROGRAMAÇÃO MATLAB. BECKER GENARO ALXE, SILVA MADIANEIRA ILHA DAIANE, DIAS SOARES HELMUTH FRANCISCO , PINHEIRO KOWALSKI LUCÉLIA. Acesso em <http://www.inf.ufsc.br/ bosco.sobral/ensino/ine5201/apostil a_matlab.pdf >. Data de acesso: 10/12/2017.

6) ESPECTROSCOPIA NO INFRAVERMELHO. UMA APRESENTAÇÃO PARA O ENSINO MEDIO. DIEGO DE OLIVEIRA LEITE, ROGERIO JUNQUEIRA PRADO. Acesso em <http://www.scielo.br/scielo.br/scielo.php?script=sci_arttext\&pid=S1806$11172012000200015>$. Data de acesso :23/07/2018. 